\title{
ANÁLISE AMBIENTAL DO PÓLO DE GUANAMBI - BA: RELAÇÃO ENTRE DADOS SOCIOECONÔMICOS E DESERTIFICAÇÃO.
}

\author{
Mariana Oliveira de Jesús ${ }^{1}$; Nacelice Barbosa Freitas ${ }^{2}$. \\ 1. Bolsista PIBIC/CNPq, Graduando do bacharelado em Geografia, Universidade Estadual de Feira de Santana, e-mail: \\ mariana.oliveira.js@gmail.com. \\ 2. Orientador, Departamento de nome, Universidade Estadual de Feira de Santana, e-mail: nacegeografic@gmail.com
}

PALAVRAS-CHAVE: Desertificação; Dados socioeconômicos; semiárido.

\section{INTRODUÇÃO}

A desertificação resulta do desgaste do solo em regiões semiáridas e subúmidas secas, decorrentes das transformações climáticas e da ação humana, o fenômeno pode ser definido como a "degradação das terras nas regiões áridas, semiáridas e subúmidas secas" (BRASIL, 1996, p. 113).

Esse processo gera significativos problemas socioambientais tais como: migrações, perda da capacidade produtiva do solo, diminuição da renda média e do consumo da população, perda da biodiversidade e ampliação da pobreza. Os baixos rendimentos econômicos da região semiárida e altos índices de pobreza estão associados a dois fatores: primeiro o clima - que favorece a escassez hídrica prejudicando assim as atividades econômicas, por exemplo, agropecuária. O segundo- as questões sociais e políticas que pode se relacionar a concentração de latifúndios e a efetividade das políticas de combate à seca (IPEA, 2015).

Tal realidade se faz presente no Pólo de Guanambi, área do presente estudo que está localizada no Sudoeste da Bahia, entre as coordenadas geográficas 14²13'30" de Latitude Sul e 42 46'53" de Longitude Oeste, e conta com 14 municípios: Palmas de Monte Alto, Caetité, Matina, Igaporã, Candiba, Urandi, Lagoa Real Sebastião Laranjeiras, Iuiú, Pindaí, Licínio Almeida, Guanambi, Malhada e Livramento de Nossa Senhora. A presente pesquisa teve como objetivo analisar os dados referentes ao Produto Interno Bruto (PIB) e da renda per capita e Rendimento Médio Mensal no Pólo, explicando a relação entre a evolução dos números, desertificação e vulnerabilidade ambiental.

\section{MATERIAL E MÉTODOS OU METODOLOGIA (ou equivalente)}

Para o desenvolvimento da pesquisa inicialmente foi realizado um referencial teóricometodológico sobre os conceitos de Desertificação, dados socioeconômicos e semiárido. No segundo momento realizou-se a coleta de dados de PIB, renda per capita e renda média mensal através dos censos Demográficos do Instituto de geografia e Estatística (IBGE) entre os anos de 2010 e 2014. Em seguida foram confeccionados tabelas e os mapas do Pólo, utilizando o software de geoprocessamento ArcVierw e ArcMap.

\section{RESULTADOS E/OU DISCUSSÃO}

Conforme o Plano Estadual de Combate à Desertificação e Mitigação dos Efeitos da Seca (PAE, 2014) as atividades de agricultura, pecuária e mineração estão acelerando o processo de desertificação e a degradação do Pólo, queimadas, exposição dos solos, desenvolvimento de ravinas e voçorocas que tornam os solos mais frágeis e ocasionam perda diversidade da vegetação. Observou-se durante a pesquisa que os municípios mais afetados pelo processo de desertificação são, Candiba, Guanambi, Iuiú, Livramento de Nossa Senhora e Malhada (JUNIOR e LOBÃO, 2011). 
A partir dos dados encontrados verifica-se, entre os anos 2010 e 2014 o crescimento dos índices socioeconômicos como renda média mensal, renda per capita e Produto Interno Bruto (PIB) devido ao aumento do investimento nos municípios do Pólo em industrialização, comércio e serviços. Conforme os dados mostrados na tabela 1, observa-se que todos os municípios do Pólo apresentaram o crescimento do PIB entre 2010 e 2014 (TABELA 1).

\section{TABELA 1: PRODUTO INTERNO BRUTO DOS MUNICI’PIOS DO PÓLO DE GUANAMBI- 2010 -} 2014

\begin{tabular}{lcc}
\hline Municípios de Guanambi 2000 & $\mathbf{2 0 1 0}$ & Rural \\
\hline Palmas de Monte Alto & 81.447 & $124.879,4$ \\
Caetité & 291.471 & 639.479 .61 \\
Matina & 33.934 & $54.805,58$ \\
Igaporã & 57.469 & $211.223,89$ \\
Candiba & 49.627 & $82.63,23$ \\
Urandi & 105.839 & $136.397,77$ \\
Lagoa Real & 44.708 & $72.595,24$ \\
Sebastião Laranjeiras & 46.011 & $64.197,59$ \\
Iuiú & 50.315 & $80.232,48$ \\
Pindaí & 52.108 & $83.844,95$ \\
Licínio de Almeida & 48.840 & $80.966,83$ \\
Guanambi & 544.907 & $1.041 .751,52$ \\
Malhada & 69.735 & $112.516,31$ \\
Livramento de Nossa Senhora & 284.508 & 384.860 \\
\hline
\end{tabular}

Fonte: IBGE, $2010-2014$

Observa-se que, de acordo com os dados apresentados, referentes aos anos de $2010 \mathrm{e}$ 2014, Guanambi conta com maior PIB. Associado a isso apresenta a maior renda média mensal, considerando que é o município do Pólo com maior número de empresas instaladas na sede, o que contribui para os maiores fluxos de pessoas para área urbana. (TABELA 1)

Identificou-se que os municípios que apresentaram os maiores índices com relação ao PIB são, Lagoa Real, Licínio e Caetité, sabendo-se que resultam da extração de minerais. Em contrapartida a extração de minérios contribui para acelerar o processo de desertificação e contaminar parte da água subterrânea por minerais radioativos (PAE, 2014). (TABELA 1)

A tabela 2 apresenta a renda per capita dos municípios do Pólo de Guanambi no período de 2010 - 2014 em cada município do Pólo de Guanambi (TABELA 2).

TABELA 2: RENDA PER CAPITA DOS MUNICIPIOS DO POLO DE GUANANBI

\begin{tabular}{lll}
\hline MUNICÍPIOS DE GUANAMBI & $\mathbf{2 0 1 0}$ & $\mathbf{2 0 1 4}$ \\
\hline Palmas de Monte Alto & $3.919,70$ & $5.589,95$ \\
Caetité & $6.133,14$ & $12.214,77$ \\
Matina & $3.047,79$ & $4.486,01$ \\
Igaporã & $3.782,36$ & $13.044,15$ \\
Candiba & $3.758,22$ & $5.664,31$ \\
Urandi & $6.414,90$ & $7.897,96$ \\
Lagoa Real & $3.208,55$ & $4.630,98$ \\
Sebastião Laranjeiras & $4.436,08$ & $5.614,13$ \\
Iuiú & $4.613,90$ & $7.113,99$ \\
Pindaí & $3.334,06$ & $5.003,28$ \\
Licínio de Almeida & $3.964,26$ & $6.245,03$ \\
Guanambi & $6.914,97$ & $12.221,92$ \\
Malhada & $4.356,26$ & $6.460,51$
\end{tabular}


Fonte: IBGE, 2010

Percebe-se que a desertificação no Pólo afeta diretamente na situação econômica dos municípios, observando que os mesmos possuem baixos índices nas rendas per capita considerando o Estado da Bahia - tanto em 2010, quanto em 2014. Os municípios de Malhada apresentou renda per capita em 2010 de 4.356,26 e em 2014 de 6.460,51, Sebastião Laranjeiras apresentou em 2010, renda per capita de 4.436,08 e em 2014 de 5.614,13. Além de Palmas apresentando renda per capita em 2010 de 3.919,70 e em 2014 de 5.589,95. A partir desses dados percebe-se que os municípios, tiveram pouco crescimento da renda entre esses quatro anos (TABELA 2).

O município de Caetité apresentou renda per capita em 2000 de 6.133,14 e em 2014 de 12.212,77 e Urandi apresentou em 2010, renda per capita de 6.414,90 e em 2014 de 7.897,96. Estes municípios têm como principal atividade econômica a indústria o que justifica as maiores rendas per capita apresentada no período de 2010, observando-se um crescimento significativo em 2014 (TABELA 2).

No ano de 2014 as maiores rendas per capita foram apresentadas por Caetité (12.214, 77), Guanambi (12.221,92), e Igaporã (13.044,15). Os dados de 2010 e 2014 permitem afirmar que houve uma evolução significativa da renda o que se atrela aos investimentos industriais (TABELA 2).

TABELA 3: RENDIMENTO MEDIO MENSAL DO PÓLO DE GUANAMBI

\begin{tabular}{ll}
\hline MUNICÍPIOS DE GUANAMBI & $\mathbf{2 0 1 0}$ \\
\hline Palmas de Monte Alto & 473,48 \\
Caetité & 733,87 \\
Matina & 426,46 \\
Igaporã & 540,67 \\
Candiba & 502,29 \\
Urandi & 708,62 \\
Lagoa Real & 436,93 \\
Sebastião Laranjeiras & 509,58 \\
Iuiú & 475,38 \\
Pindaí & 487,78 \\
Licínio de Almeida & 476,13 \\
Guanambi & 849,92 \\
Malhada & 478,21 \\
Livramento de Nossa Senhora & 621,92 \\
\hline
\end{tabular}

Fonte: IBGE, 2010

Durante a realização da pesquisa deparou-se com a dificuldade de reunir os dados referentes à renda média mensal dos municípios do Pólo, por não se ter disponibilizado pelo IBGE, nem a SUDENE os números do ano de 2014. Mas a partir da leitura dos números indicados na tabela 3, observa-se que o rendimento mensal dos municípios que integram o Pólo, são inferiores a um salário mínimo em 2010, porque as bases salariais variam entre R\$ 400,00 e $\mathrm{R} \$ 849,00$ reais. Os municípios que detém maior base de rendimento mensal em 2010 foram, Caetité $(733,87 \$)$, Urandi $(708,62 \$)$ e Livramento de Nossa Senhora $(621,92 \$)$. São também os que apresentam as maiores rendas per capita e que tem produtividade significativa no setor agropecuário no que se refere ao PIB. 


\section{CONSIDERAÇÕES FINAIS}

A pesquisa permite afirmar que a expansão do processo de desertificação no Pólo de Guanambi, decorre do uso inadequado do solo, associado às práticas de agricultura e mineração, trazendo significativas implicações para os municípios, tais como a redução da população, baixos níveis de renda média mensal e renda per capita, assim como o PIB. Assim, o processo de desertificação nos municípios pesquisados, reflete na economia local e regional, especialmente no que concernem as atividades do setor agropecuário. Conforme análise dos dados, entre os anos 2010 e 2014, os maiores indicadores econômicos situam-se nos centros urbanos dos Polos, como Guanambi, Caetité e Urandi entre essas décadas pesquisadas. Nessa perspectiva, os municípios que apresentaram evolução nos números, tanto no que se refere a renda média mensal e per capita, quanto do PIB, pressupondo-se que houve maiores investimentos no setor industrial, que passou a ser a principal atividade econômica. Assim, os dados sobre renda média mensal, indicam a redução dos recursos para a população rural investir em atividades no campo, o que leva os agricultores a explorar cada vez mais as áreas rurais de forma inadequada, aprofundando o nível de degradação ambiental, levando ao endividamento dos agricultores, que, por vezes, são obrigados a vender a pequena propriedade. Para o crescimento econômico dos Polos, torna-se necessário a implantação de políticas públicas que tenham como proposta a distribuição de renda, e a definição de instrumentos que visem orientar o agricultor nas práticas cultivo sustentável, mitigando os efeitos da seca e a ampliação do processo de desertificação.

\section{REFERÊNCIAS}

BRASIL, Senado Federal. Conferência das Nações Unidas sobre Meio Ambiente e Desenvolvimento. Rio 92. Agenda 21. Brasília: Senado Federal; Subsecretaria de Edições Técnicas, 1996. IBGE - INSTITUTO BRASILEIRO DE GEOGRAFIA E ESTATÍSTICA. Censo Demográfico 2010.

IBGE - INSTITUTO BRASILEIRO DE GEOGRAFIA E ESTATÍSTICA. Censo Demográfico 2014.

JUNIOR, Israel de Oliveira; LOBÃO, Jocimara de Souza Brito. Apropriação das terras no semiárido da Bahia: diagnosticando o processo de desertificação no polo de Guanambi. Anais: XV seminário de iniciação científica, Feira de Santana: UEFS, 2011. Disponível em: <http://www.Xvsemic.esy.es/upload/2011/2011XV-007ISR030-100.pdf>. Acesso em 5 de maio de 2018.

PAE. Plano Estadual de Combate à Desertificação e Mitigação dos Efeitos da Seca, 2014. 